\title{
Articular cartilage gene expression patterns in the tissue surrounding the impact site following applications of shear and axial loads
}

R. S. McCulloch ${ }^{1,2^{*}}$ (D, P. L. Mente ${ }^{1 \wedge}$, A. T. O'Nan ${ }^{3}$ and M. S. Ashwell ${ }^{3}$

\begin{abstract}
Background: Osteoarthritis is a degradative joint disease found in humans and commercial swine which can develop from a number of factors, including prior joint trauma. An impact injury model was developed to deliver in vitro loads to disease-free porcine patellae in a model of OA.

Methods: Axial impactions (2000 N normal) and shear impactions (500 N normal with induced shear forces) were delivered to 48 randomly assigned patellae. The patellae were then cultured for 0,3 , 7, or 14 days following the impact. Specimens in the tissue surrounding the loading site were harvested and expression of 18 OA related genes was studied via quantitative PCR. The selected genes were previously identified from published work and fell into four categories: cartilage matrix, degradative enzymes, inflammatory response, and apoptosis.

Results: Type II collagen (Co/2a1) showed significantly lower expression in shear vs. axial adjacent tissue at day 0 and 7 (fold changes of $0.40 \& 0.19$, respectively). In addition, higher expression of degradative enzymes and Fas, an apoptosis gene, was observed in the shear specimens.

Conclusions: The results suggest that a more physiologically valid shear load may induce more damage to surrounding articular cartilage than a normal load alone.
\end{abstract}

Keywords: Osteoarthritis, Porcine, Articular injury

\section{Background}

Although osteoarthritis (OA) is the most common joint disorder in humans [1], the multi-factorial pathogenesis of $\mathrm{OA}$ is still not completely understood [2,3]. Joint trauma, however, is a known causative factor in the development of OA [2, 4]. Controlled experimental injury models in an in vitro setting [5-11] provide the ability to precisely control loading to study the early stages of articular cartilage degradation in OA. Most impact studies use loading normal to the cartilage surface, however a realistic physiological trauma will most likely generate large shear forces. An axial load will

\footnotetext{
* Correspondence: mcculloch@gonzaga.edu

Deceased

'Joint Department of Biomedical Engineering, North Carolina State University, Raleigh, NC, USA and University of North Carolina, Chapel Hill, North Carolina, USA

2Department of Human Physiology, Gonzaga University, 502 E Boone Ave, Spokane, WA 99258, USA

Full list of author information is available at the end of the article
}

cause a compression of the cartilage surface, and subsequent movement of fluid through the matrix following compression of the tissue. However, our work with three dimension load cells indicates that the while some shear loading is present at the surface, these forces are not large. A realistic trauma that may lead to OA, such as a fall, sports injury, car crash, would likely involve multi-axial loading with much higher shear forces. Thus, it was our aim to intentionally deliver higher shear loads to better model what may happen in a physiological trauma.

ACL transection models are used to study in vivo progression of OA [12], however these models induce general instability and make it hard to precisely control the degree of load changes. Other models include disuse models of OA [13], however these likely result in different pathways than that induced by a traumatic injury. Many models use cartilage explants that are removed from the surrounding tissue and then subjected to 
loading [14]. However, these models make it hard to differentiate whether the changes were due to the harvesting of the explant or the intentionally induced trauma.

Degenerative joint disease is not limited to only humans. Lameness is one of the primary reasons for culling in commercial swine, accounting for $22.5 \%$ of the culled sows in Southern China [15]. Structural lameness and leg weakness have been issues in commercial swine for decades and continues to contribute to sow longevity issues [16]. Kirk and coworkers found many of the locomotive problems found in sows were due to arthritis [17]. In our previous work (unpublished), we found that nearly $75 \%$ of the femoral heads from culled sows examined in a slaughterhouse have naturally occurring osteoarthritis at different stages of degeneration. Even in growing pigs, degenerative joint disease is a major cause of lameness [18], where trauma is a common cause of that lameness [19]. Because of the occurrence and similarities of OA in pigs, porcine models of OA have been used in both in vitro and in in vivo models to study OA and its treatments. [20-23]

In our previous work, we developed a shear injury model of OA and evaluated gene expression changes in the articular cartilage directly below the impact injury site [24]. In the present work, expression changes in the tissue adjacent to the loading site were evaluated. It was hypothesized that shear impacts would generate more degradative changes to adjacent tissue than normal impacts.

\section{Methods}

Forty-eight (48) intact porcine knee joints were obtained from a local slaughterhouse and the patellae were sterilely removed. In a custom testing apparatus using a servo-hydraulic load frame, an impact was delivered to each patella orthogonal to the articular surface via a stainless-steel impactor of $10 \mathrm{~mm}$ radius and $10 \mathrm{~mm}$ length. A custom holder was manufactured for the patellae, to position them with the facet orthogonal to the direction of the axial impact. The holder had a spherical depression, and the patellae were potted in sterile Polymethylmethacrylate (PMMA bone cement) in a spherical shape to allow for proper positioning and orientation of the patellae. The axial impaction (axial) delivered a load of $2000 \mathrm{~N}$ normal to the surface [7]. For the shear impaction (shear), once a $500 \mathrm{~N}$ normal load was reached, the patella was immediately mechanically displaced (via a second load frame) using a cable and pulley arrangement $10 \mathrm{~mm}$ tangentially to induce shear forces in the cartilage, resulting in mean shear forces at the impactor tip of $198 \pm 59.2 \mathrm{~N}$ (Fig. 1). Additionally, a set of 24 control specimens were processed in the same manner, but without impacts.

After impact, the patellae were placed into culture (Culture media: Dulbecco's MEM/Ham's F12 with 10\% fetal calf serum, ascorbic acid $(25 \mu \mathrm{g} / \mathrm{ml})$ with penicillin $100 \mathrm{units} / \mathrm{ml}$, streptomycin $100 \mu \mathrm{g} / \mathrm{ml}$, and amphotericin B $25 \mu \mathrm{g} / \mathrm{ml}$ ) for $0,3,7$, or 14 days. At each time point, full thickness slices of cartilage were harvested at the

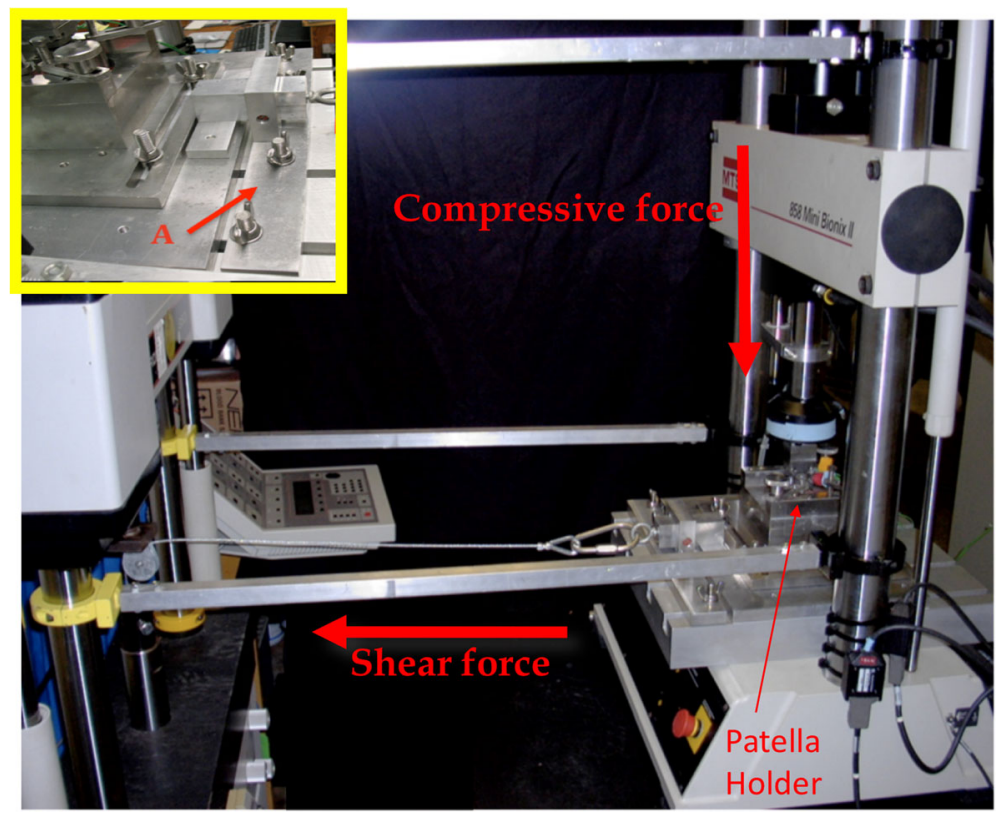

Fig. 1 Mechanical impact testing setup. The patella holder can be seen to the right, positioned in the first load frame. For pure axial impactions, the cross-head of the servo-hydraulic load frame on the right delivered an orthogonal load to the patella facet. For impactions with elevated shear, the load frame on the right delivered an axial impaction, while the load frame to the left displaced the patella tangentially $10 \mathrm{~mm}$ to induce elevated shear forces. The stop bar in the inset image shows the stop bar (A) that limited tangential movement to $10 \mathrm{~mm}$ 
area of impact (AOI) and from tissue adjacent to the impact site (ADJ). The samples were flash frozen in liquid $\mathrm{N}_{2}$ and stored at $-80^{\circ} \mathrm{C}$. The AOI specimens for the axial impactions were $5 \times 10 \mathrm{~mm}$, to represent the area under the impactor tip contact, and the AOI specimens for the shear impactions were $10 \times 10 \mathrm{~mm}$ to accommodate the tangential displacement of the impactor during loading. In each case, ADJ specimens of $3 \times 10 \mathrm{~mm}$ were harvested from the proximal and distal ends of the impaction sites (Fig. 2).

Gene expression analysis was completed using methods previously described [24, 25], briefly: RNA was extracted using Tri Reagent (Molecular Research Center Inc., Cincinnati, $\mathrm{OH}$ ) after grinding the cartilage specimens to a fine powder. RNA purity was assessed (Nanodrop-1000, Thermo Scientific, Wilmington, DE), and was then reverse transcribed (High Capacity cDNA Reverse Transcription Kit, Applied Biosystems Inc., Foster City, CA). Quantitative real-time PCR (qPCR) was performed, and the genes of interest were normalized to a panel of 4 previously identified housekeeping genes [25]. See Table 1 regarding

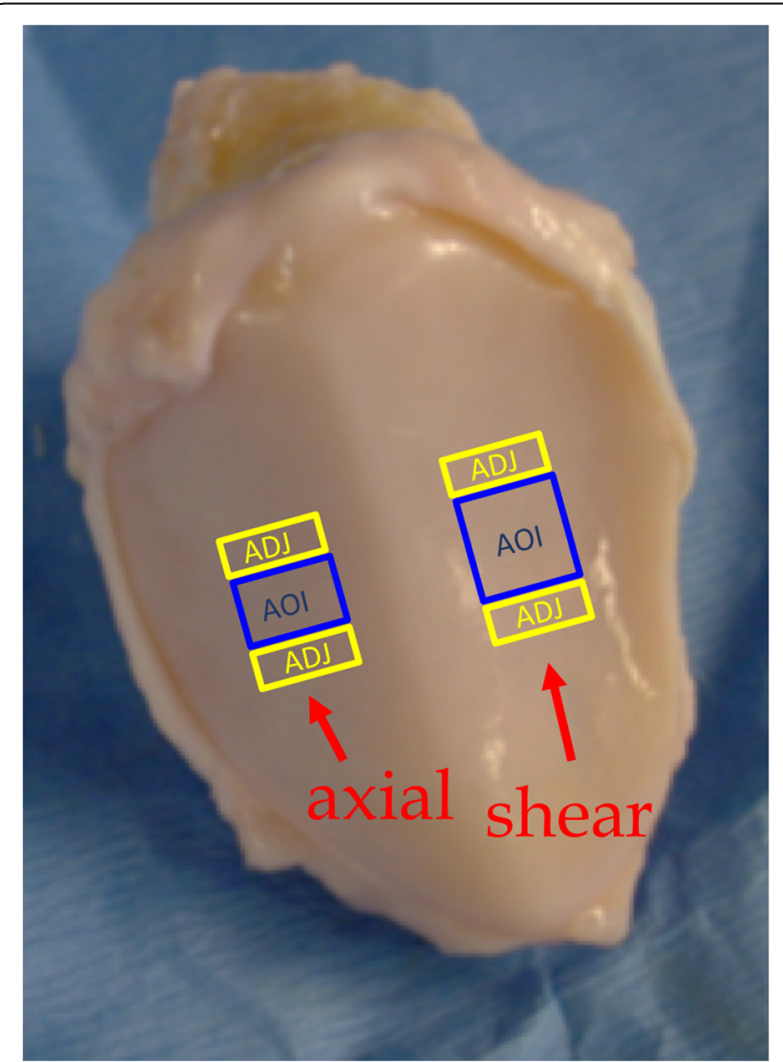

Fig. 2 Specimen locations. Full-thickness cartilage specimens were harvested from the location directly below the impact site (AOI sample in blue), and in the tissue adjacent to the impaction site (ADJ sample in yellow). The relative size of the axial specimens is shown on the left, and the shear on the right. This figure is for demonstration only, actual patellae were given identical treatments on each facet full gene and primer information, and please refer to Additional file 1 for primer design and qPCR analysis. Eighteen genes associated with early stage OA were evaluated: 1) Cartilage Matrix: Col1a1, Col2a1, Acan, Sox9, Opn, Comp; 2) Degradative Enzymes and Inhibitors: Mmp1, Mmp3, Mmp13, Timp1, Timp2, Adamts5;3) Inflammatory Response and Signaling: Ihh, Tgfb, Inos, Chi3l1; and 4) Apoptosis: Casp8, Fas.

The relative gene expression levels were compared between the ADJ specimens for axial and shear impacts, and between ADJ and their associated AOI specimens. Differences in AOI specimens were reported previously [24]. A linear mixed model (SAS, SAS Institute, Cary, $\mathrm{NC)}$ was used to evaluate differences in fold changes, following the methods of Steibel et al. [26]. The family-wise error rate was controlled using the false discovery rate method (FDR) [27] to generate a $q$-value. Because each time point/impact combination had a small number of samples, the q-value significance threshold was set at $q<0.2$. This allowed detection of changes without being overly restrictive, and due to how FDR controls for error in results deemed significant, a threshold of up to 0.5 may be acceptable [27].

\section{Results}

The 72 patellae (36 right, 36 left) were randomly assigned to a treatment and time point, with 6 patellae at each combination (axial, shear, control; and 0, 3, 7, 14 days in culture). Fold changes (FC) were compared between shear and axial ADJ tissue (Fig. 3). In the cartilage matrix, Col2a1 expression was significantly lower in shear vs. axial specimens at day 0 (FC 0.40) and day 7 (FC 0.19). Sox 9 was higher in shear specimens on day 3 (FC 2.46), and Acan was higher in shear specimens on day 14 (FC 2.96). In the degradative enzymes, Mmp3 was elevated on day 0 (FC 4.05), whereas Timp1 was elevated on day 14 (FC 2.01) in the shear samples. For the inflammatory response genes, expression of Chi3l1 was lower in shear specimens on day 3 (FC 0.37), and $\mathrm{Tg} f b$ was lower in shear specimens on day 7 (FC 0.55). For the apoptosis related genes, Fas demonstrated higher expression in the shear specimens at day 0 (FC 2.22) and day 14. (FC 2.19).

The ADJ tissue specimens were also compared to their associated AOI specimens to examine fold change differences at each time point (Table 2). Colla1 was elevated in both axial and shear ADJ tissue at day 0. However, Col2a1 showed lower expression in shear ADJ tissue on day 7. Mmp3 and Adamts5 were both more highly expressed in the shear ADJ specimens at the last time point. Casp 8 was lower in shear ADJ vs AOI tissue on both day 0 and day 14 .

Finally, shear ADJ specimens were compared to control specimens at their associated time points (Fig. 4). 
Table 1 Gene primer information

\begin{tabular}{|c|c|c|c|c|}
\hline Gene Name & Sequence $\left(5^{\prime}->3^{\prime}\right)$ & $\begin{array}{l}\text { Annealing } \\
\text { Temp }\end{array}$ & $\begin{array}{l}\text { Amplicon } \\
\text { length }\end{array}$ & NCBI Number \\
\hline \multicolumn{5}{|l|}{ Cartilage Matrix } \\
\hline \multirow[t]{2}{*}{ Collagen, Type I, Alpha 1 (Col1a1) } & F: CAACCGCTTCACCTACAGC & & & \\
\hline & R: TITTGTATTCGATCACTGTCTTGCC & 60 & 101 & AK236626 \\
\hline \multirow[t]{2}{*}{ Collagen, Type II, Alpha 1 (Col2a1) } & F: GAGAGGTCTTCCTGGCAAAG & & & \\
\hline & R: AAGTCCCTGGAAGCCAGAT & 60 & 118 & AF201724.1 \\
\hline \multirow[t]{2}{*}{ Aggrecan (Acan) } & F: TGCAGGTGACCATGGCC & & & \\
\hline & R: CGGTAATGGAACACAACCCCT & 60 & 79 & AF201722b \\
\hline \multirow[t]{2}{*}{ SRY (sex determining gene region Y) box-9 (Sox9) } & F: CAGGGCTCTGTGCTCTACTCC & & & \\
\hline & R: GGGTTACGGTCTITCTTCGGT & 60 & 230 & NM_213843.1 \\
\hline \multirow[t]{2}{*}{ Osteopontin (Opn) } & F: CCGCAGCCAGGAGCAGTC & & & \\
\hline & R: GTTGATCTCAGAAGACGCACTCTC & 55 & 214 & NM_214023.1 \\
\hline \multirow[t]{2}{*}{ Cartilage oligometric matrix protein (Comp) } & F: GGCTGGAAGGACAAGACATC & & & \\
\hline & R: CCTCATAGAACCGCACTCTG & 55 & 82 & XM_003123529.1 \\
\hline \multicolumn{5}{|l|}{ Degradative Enzymes \& Inhibitors } \\
\hline \multirow[t]{2}{*}{ Matrix metalloprotease-1 (Mmp1) } & F: TGATGGACCTGGAGGAAACC & & & \\
\hline & R: GAGCAGCCACACGATACAAG & 59 & 131 & NM_001166229 \\
\hline \multirow[t]{2}{*}{ Matrix metalloprotease-3 (Mmp3) } & F: GATGTTGGTTACTTCAGCAC & & & \\
\hline & R: ATCATTATGTCAGCCTCTCC & 50 & 197 & NM_001166308.1 \\
\hline \multirow[t]{2}{*}{ Matrix metalloprotease-13 (Mmp13) } & F: CCAAAGGCTACAACTTGTITCTTG & & & \\
\hline & R: TGGGTCCTTGGAGTGGTCAA & 60 & 77 & AF069643 \\
\hline \multirow[t]{2}{*}{ TIMP Metallopeptidase Inhibitor-1 (Timp1) } & F: CCTCGTACCAGCGTTATG & & & \\
\hline & R: CGTTCCACAGTTGTCCAG & 59 & 177 & NM_213857.1 \\
\hline \multirow[t]{2}{*}{ TIMP Metallopeptidase Inhibitor-2 (Timp2) } & F: ATATACGAGAACACCAGACC & & & \\
\hline & R: GGAATGATTACAACGGATGC & 59 & 152 & AK237154.1 \\
\hline \multirow{2}{*}{$\begin{array}{l}\text { ADAM Metallopeptidase with Thrombospondin } \\
\text { Type } 1 \text { Motif } 5 \text { (Adamts5) }\end{array}$} & F: CGCTGCCACCACACTCAA & & & \\
\hline & R: CGTAGTGCTCCTCATGGTCATCT & 60 & 80 & NM_007038.3 \\
\hline \multicolumn{5}{|l|}{ Inflammatory Response } \\
\hline \multirow[t]{2}{*}{ Indian Hedgehog (Ihh) } & F: CAGCGGGCGCTATGAAGGCA & & & \\
\hline & R: GGTCCTTGCAGCGCTGGGTC & 60 & 140 & XM_001925486.1 \\
\hline \multirow[t]{2}{*}{ Transforming growth factor $\beta$ (Tgfb) } & F: GGAGTGGCTGTCCTTTGATGT & & & \\
\hline & R: AGTGTGTTATCTITGCTGTCA & 60 & 117 & NM_214015.1 \\
\hline \multirow[t]{2}{*}{ nitric oxide synthase 2 , inducible (Inos) } & F: TGAATTTGTCAACCTGTATTAC & & & \\
\hline & R: CTITGTTACCGCTTCCAC & 53 & 82 & NM_001143690.1 \\
\hline \multirow[t]{2}{*}{ Chitinase-3-like protein 1 (Chi3/1) } & F: TGACGCTCTATGACACAC & & & \\
\hline & R: GGCTAGGTCCAGTCCATC & 62 & 194 & NM_001001540 \\
\hline \multicolumn{5}{|l|}{ Cell Proliferation and Apoptosis } \\
\hline \multirow[t]{2}{*}{ Caspase-8 (Casp8) } & F: TGGGCAAACAGATGCCACAACCT & & & \\
\hline & R: CCCCTTCAATCTAGCCCACCCCC & 60 & 153 & NM_001031779.2 \\
\hline \multirow[t]{2}{*}{ Fas (TNF receptor superfamily, member 6) (Fas) } & F: TAGAGTTTGTGATGGAGAA & & & \\
\hline & R: ATTGAGAAGTGTGACAGA & 53 & 107 & NM_213839.1 \\
\hline
\end{tabular}

Full names with abbreviations, primer sequences, annealing temperatures, amplicon length, and NCBI numbers 
Colla1 was more highly expressed in shear specimens on day 0 vs control (FC 11.22) while it demonstrated lower expression on day 14 (FC 0.12). On day 7 Col2a 1 showed lower expression in the shear specimens (FC 0.34). Mmp1 showed lower expression than control on day 3,7 , \& 14 (FC $0.49,0.45$, \& 0.47 respectively). Mmp-13 showed higher expression on day 0 in the shear specimens (FC 2.82). Timp-1 was demonstrated lower expressed in shear specimens on day 3 (FC .57). Adamts-5 was more highly expressed in shear specimens on day 0 (FC 1.97). Ihh showed lower expression in shear specimens on day 7 (FC 0.50). Chi $3 l 1$ was less expressed in shear specimens compared to control on day 3 (FC 0.30).

\section{Discussion}

The goal of this study was to compare two in vitro loading scenarios, one with primarily normal loading, and another with elevated shear loading. The elevated shear loading is likely more representative of true physiological loading. It was believed that shear loading would induce more deleterious effects in the adjacent non-impacted tissue. Our results suggest that this was the case, with Col2a1 downregulated in shear ADJ tissue, Mmps showing higher expression, and elevated levels of Fas expression.

Though Col1a1 levels were elevated early in shear vs axial, the difference was not significant, and the expression did not remain elevated. However, Col2a1 remained lower at all time points in shear ADJ tissue, and tended to be lower than shear AOI. Similarly, Colla1 was more highly expressed in shear specimens vs. control, and Col2a1 showed lower expression in the shear specimens vs. control. This finding is notable, as Col2a1 is the primary collagen found in articular cartilage, and its depression may indicate that the chondrocytes are not effectively repairing the damage, especially when taken in light of the more highly expressed levels of Col1a1. This could suggest that the chondrocytes are reverting to a dedifferentiated state following the loading [8, 28, 29]. The elevation of Sox9 and Acan indicates a repair effort is being mounted [30]. Taken together with the collagen expression differences, the cells may be attempting

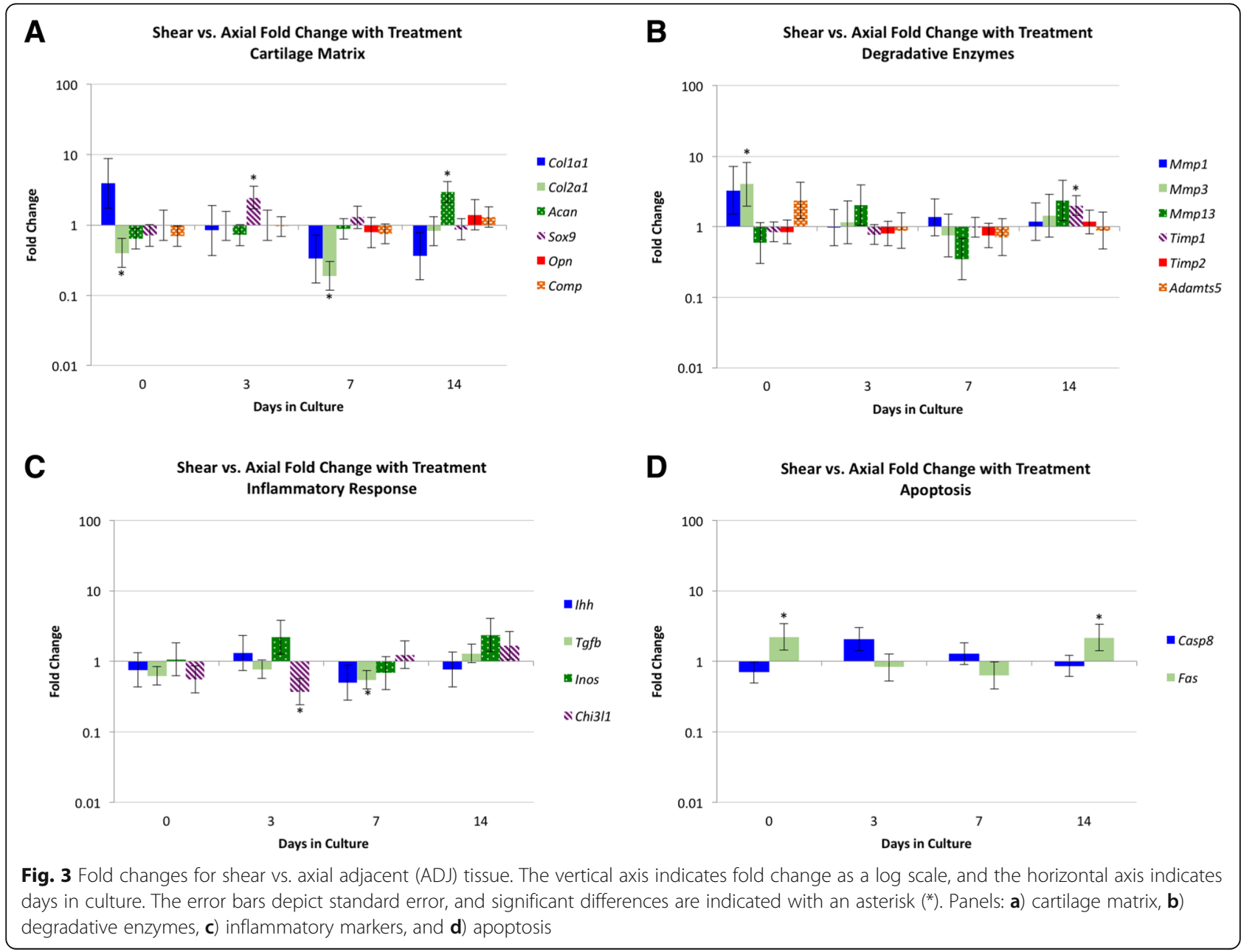


Table 2 Differential gene expression between the tissue adjacent to the impact site (ADJ) and the area of impact (AOI) at each time point for each type of impact (axial and shear)

\begin{tabular}{|c|c|c|c|c|c|c|c|c|}
\hline \multirow[t]{3}{*}{ Gene } & \multicolumn{4}{|c|}{ Fold Changes } & \multicolumn{4}{|c|}{ Fold Changes } \\
\hline & \multicolumn{4}{|c|}{ Axial ADJ vs. AOI } & \multicolumn{4}{|c|}{ Shear ADJ vs. AOI } \\
\hline & Day 0 & Day 3 & Day 7 & $\overline{\text { Day } 14}$ & Day 0 & Day 3 & Day 7 & Day 14 \\
\hline \multicolumn{9}{|c|}{ Cartilage Matrix } \\
\hline Colla1 & 13.50 & 2.36 & 1.53 & 0.22 & 10.03 & 0.40 & 0.93 & 0.54 \\
\hline Col2al & 0.78 & 1.42 & 0.81 & 1.03 & 0.57 & 0.57 & 0.37 & 0.78 \\
\hline Acan & 1.06 & 1.26 & 0.96 & 0.73 & 1.03 & 0.78 & 0.70 & 1.04 \\
\hline Sox9 & 0.62 & 0.49 & 0.82 & 1.31 & 0.50 & 0.96 & 1.04 & 0.39 \\
\hline Opn & 2.89 & 1.19 & 1.06 & 2.75 & 2.99 & 0.87 & 0.66 & 1.46 \\
\hline Comp & 0.87 & 0.69 & 0.90 & 1.07 & 1.48 & 0.71 & 0.90 & 0.97 \\
\hline \multicolumn{9}{|c|}{ Degradative Enzymes \& Inhibitors } \\
\hline Mmp1 & 0.55 & 1.26 & 0.49 & 1.05 & 0.64 & 1.10 & 1.37 & 3.38 \\
\hline Mmp3 & 0.52 & 2.23 & 0.70 & 1.90 & 0.89 & 1.60 & 0.16 & 4.90 \\
\hline Mmp13 & 0.96 & 1.12 & 0.88 & 0.81 & 1.67 & 0.42 & 1.20 & 2.70 \\
\hline Timp1 & 1.45 & 0.85 & 0.77 & 0.87 & 0.92 & 0.74 & 0.95 & 1.41 \\
\hline Timp2 & 2.44 & 2.73 & 0.91 & 1.76 & 0.78 & 0.94 & 0.97 & 1.31 \\
\hline Adamts 5 & 1.84 & 1.81 & 0.94 & 0.86 & 2.17 & 1.07 & 0.81 & 5.24 \\
\hline \multicolumn{9}{|c|}{ Inflammatory Response \& Signaling } \\
\hline Ihh & 1.04 & 3.53 & 1.85 & 0.74 & 0.39 & 1.69 & 0.41 & 0.34 \\
\hline Tgfb & 1.27 & 0.98 & 1.24 & 1.46 & 1.54 & 1.20 & 0.76 & 1.10 \\
\hline Inos & 0.36 & 0.87 & 1.39 & 1.18 & 1.11 & 1.15 & 1.54 & 1.35 \\
\hline Chi3/1 & 1.00 & 0.93 & 0.96 & 0.75 & 0.51 & 0.63 & 1.14 & 0.79 \\
\hline \multicolumn{9}{|c|}{ Cell Proliferation \& Apoptosis } \\
\hline Casp8 & 0.63 & 0.56 & 0.84 & 1.34 & 0.50 & 1.01 & 1.05 & 0.39 \\
\hline Fas & 0.37 & 1.36 & 1.70 & 1.24 & 1.95 & 1.24 & 0.58 & 1.49 \\
\hline
\end{tabular}

Significant $q$-values $(q<.2)$ are indicated by bold type

recovery from the trauma, but with responses that are ineffective for proper tissue repair.

The chondrocytes show elevated levels of degradative enzymes, and at later time points, elevated levels of an associated inhibitor, consistent with the belief that a repair attempt is being mounted. Early elevation of degradative enzymes (Mmps) in shear vs axial ADJ and in shear ADJ vs AOI, and in shear ADJ vs. control indicates a chondrocyte response to the trauma and attempt to effect repairs, and suggests that shear loads are more damaging, likely due to additional forceful fluid movement through the matrix. This is consistent with other work that has found elevated levels of Mmps in early OA [10, 31]. Also, Adamts5, an aggrecanase, was elevated more in the shear $\mathrm{ADJ}$ vs AOI tissue at the last time point, which suggests more matrix breakdown in the shear adjacent tissue. Following the early elevated degradative enzyme expression, the increase of timp1 (an inhibitor of Mmps) at the last time point may suggest the chondrocytes are attempting to limit matrix breakdown, consistent with the idea that the cells are attempting repairs via initial breakdown that is stemmed at later points following the injury.

Ihh has been associated with chondrocyte hypertrophy and has been found to be elevated in OA [32], and its lower expression in our shear ADJ vs AOI tissue may be the result of the aforementioned dedifferentiation of the chondrocytes, therefore generating inconsistent and ineffective repair efforts. Fas is associated with apoptosis, and its elevation in shear vs axial ADJ tissue may indicate more cell death, in-line with work showing its increase at OA lesions [33].

\section{Conclusions}

If we can gain a better understanding of the very early degenerative changes that precede full blown OA we will be better able to identify potential targets for therapeutic intervention, treat the disease, and prevent the debilitating changes that occur further down the road, having dual benefit in human medicine as well as sustainable pork production. The results presented here show the effects on surrounding tissue when a more 

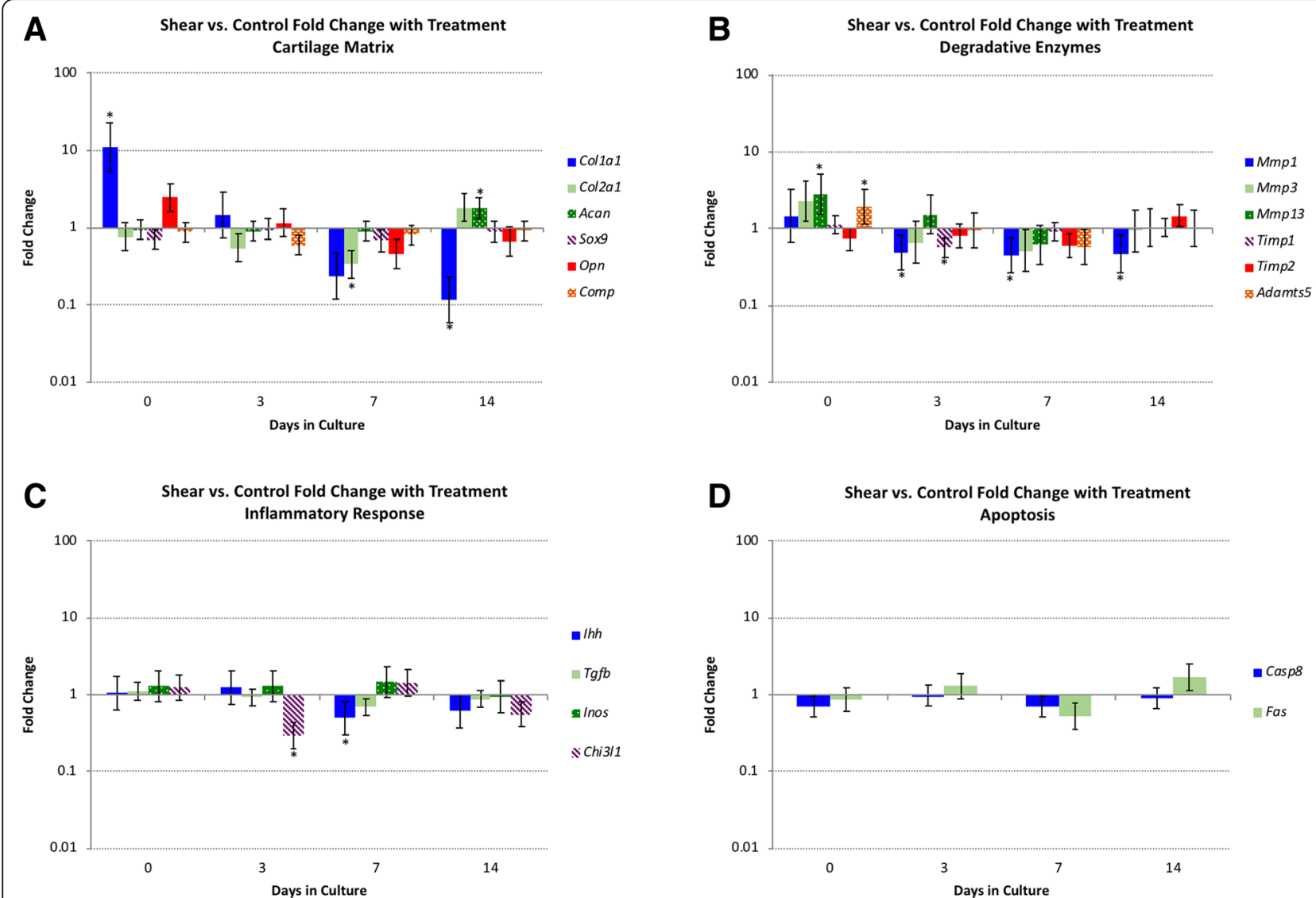

Fig. 4 Fold changes for shear adjacent (ADJ) vs. control tissue. The vertical axis indicates fold change as a log scale, and the horizontal axis indicates days in culture. The error bars depict standard error, and significant differences are indicated with an asterisk $\left({ }^{*}\right)$. Panels: a) cartilage matrix, b) degradative enzymes, c) inflammatory markers, and $\mathbf{d}$ ) apoptosis

realistic loading model is used to simulate OA in vitro. Our findings suggest that shear loads may be more damaging to surrounding tissue than a normal load alone. In the shear specimens, the adjacent tissue showed reduced levels of appropriate collagen expression, and increased expression of degradative enzymes and an apoptosis related gene. This suggests chondrocytes in the shear tissue responded with attempts at repairs but with an ineffective response.

\section{Additional file}

Additional file 1: Contains details of primer design and the $\mathrm{qPCR}$ procedure used for this study. (DOCX $32 \mathrm{~kb}$ )

\section{Acknowledgements}

The authors would like to thank Christian Maltecca, Ph.D. for his assistance in developing the mixed model used for analysis of the results.

\section{Funding}

Funding for this work was provided by National Institute of Arthritis and Musculoskeletal and Skin Diseases (NIAMS) / National Institute of Health Grant 1 R03 AR054557-01A1. The funding agency was not involved in any aspects of the study design, including data collection, interpretation of data or manuscript preparation.

Availability of data and materials

The datasets used during the current study are available from the corresponding author on reasonable request.

\section{Authors' contributions}

RSM conducted the experiment and drafted the manuscript. PLM and MSA developed the experimental design, assisted in conducting the experiment, and MSA helped with drafting the manuscript. ATO assisted with sample preparation and results analysis. All authors (with the exception of PLM deceased) read and approved the final manuscript.

\section{Ethics approval and consent to participate}

The samples used in this study were obtained from a local meat processing plant, therefore the animals were slaughtered and introduced into the food supply regardless of this experiment, allowing knowledge to be gained without having to sacrifice additional animals and not requiring IACUC approval. The ethics committee deemed no oversight was required as the tissue was a by-product of normal slaughterhouse operations and no animals were sacrificed for the purpose of this study. Because no oversight was deemed necessary, we did not require written consent, and verbal consent was provided by Andrea Neese of Neese Sausage to use the obtained animal tissue for research purposes.

Consent for publication

Not applicable. 


\section{Competing interests}

The authors declare that they have no competing interests.

\section{Publisher's Note}

Springer Nature remains neutral with regard to jurisdictional claims in published maps and institutional affiliations.

\section{Author details}

'Joint Department of Biomedical Engineering, North Carolina State University, Raleigh, NC, USA and University of North Carolina, Chapel Hill, North Carolina, USA. ${ }^{2}$ Department of Human Physiology, Gonzaga University, 502 E Boone Ave, Spokane, WA 99258, USA. "3Department of Animal Science, North Carolina State University, 120 Broughton Dr, Raleigh, NC 27695, USA.

Received: 24 April 2018 Accepted: 6 December 2018

Published online: 22 December 2018

\section{References}

1. Arden N, Nevitt MC. Osteoarthritis: epidemiology. Best Pract Res Clin Rheumatol. 2006;20:3-25.

2. Rai MF, Duan X, Quirk JD, Holquin N, Schmidt EJ, Chinzei N, Silva MJ, Sandell LJ. Post-traumatic osteoarthritis in mice following mechanical injury to the synovial joint. Sci Rep. 2017:7:45223.

3. Goldring MB, Culley KL, Otero M. Pathogenesis of osteoarthritis in General. Cham, Switzerland: Springer; 2017.

4. Buckwalter JA, Lane NE. Athletics and osteoarthritis. Am J Sports Med. 1997; 25:873-81.

5. Ficklin T, Thomas G, Barthel JC, Asanbaeva A, Thonar EJ, Masuda K, Chen AC, Sah RL, Davol A, Klisch SM. Articular cartilage mechanical and biochemical property relations before and after in vitro growth. J Biomech. 2007:40: 3607-14.

6. Wilson W, van Burken C, van Donkelaar C, Buma P, van Rietbergen B, Huiskes R. Causes of mechanically induced collagen damage in articular cartilage. J Orthop Res. 2006;24:220-8.

7. Ashwell MS, O'Nan AT, Gonda MG, Mente PL. Gene expression profiling of chondrocytes from a porcine impact injury model. Osteoarthr Cartil. 2008; 16:936-46.

8. Aigner T, Dudhia J. Genomics of osteoarthritis. Curr Opin Rheumatol. 2003; 15:634-40

9. Salzmann GM, Nuernberger B, Schmitz P, Anton M, Stoddart MJ, Grad S, Milz S, Tischer T, Vogt S, Gansbacher B. Physicobiochemical synergism through gene therapy and functional tissue engineering for in vitro chondrogenesis. Tissue Eng Part A. 2009:15:2513-24.

10. Aigner T, Zien A, Hanisch D, Zimmer R. Gene expression in chondrocytes assessed with use of microarrays. J Bone Jt Surg. 2003:85:117-23.

11. Kapitanov GI, Ayati BP, Martin JA. Modeling the effect of blunt impact on mitochondrial function in cartilage: implications for development of osteoarthritis. PeerJ. 2017;5:e3468.

12. Maerz T, Newton MD, Kurdziel MD, Altman P, Anderson K, Matthew HW, Baker KC. Articular cartilage degeneration following anterior cruciate ligament injury: a comparison of surgical transection and noninvasive rupture as preclinical models of post-traumatic osteoarthritis. Osteoarthr Cartil. 2016;24(11):1918-27

13. Wiegant $K$, Intema F, Van Roermund PM, Barten-van Rijbroek AD, Doornebal A, Hazewinkel HA, Lafeber FP, Mastbergen SC. Evidence of cartilage repair by joint distraction in a canine model of osteoarthritis. Arthritis Rheumatol. 2015;67(2):465-74

14. Martin JA, Anderson DD, Goetz JE, Fredericks D, Pedersen DR, Ayati BP, Marsh JL, Buckwalter JA. Complementary models of post-traumatic osteoarthritis reveal cellular responses to contact stress that damage articular cartilage and present targets for intervention. J Orthop Res. 2017; 35(3):515.

15. Zhao Y, Liu X, Mo D, Chen Q, Chen Y. Analysis of reasons for sow culling and seasonal effects on reproductive disorders in southern China. Anim Reprod Sci. 2015:159:191-7.

16. Crenshaw TD. Arthritis or OCD-identification and prevention. Adv Pork Prod. 2006:17:199.

17. Kirk RK, Svensmark B, Ellegaard LP, Jensen HE. Locomotive disorders associated with sow mortality in Danish pig herds. Transbound Emerg Dis. 2005:52:423-8
18. Stavrakakis S, Guy JH, Syranidis I, Johnson GR, Edwards SA. Pre-clinical and clinical walking kinematics in female breeding pigs with lameness: a nested case-control cohort study. Vet J. 2015;205:38-43.

19. Muirhead MR, Alexander TJL. Chapter 9: Managing health in the weaner, grower and finishing periods. In: Carr J, editor. Managing Pig Heath: A Reference for the Farm. 2nd ed; 2013. p. 388.

20. Lee KB, Hui JH, Song IC, Ardany L, Lee EH. Injectable mesenchymal stem cell therapy for large cartilage defects-a porcine model. Stem Cells. 2007; 25(11):2964-71.

21. Gelse K, Mühle C, Franke O, Park J, Jehle M, Durst K, Göken M, Hennig F, Mark KV, Schneider H. Cell-based resurfacing of large cartilage defects: longterm evaluation of grafts from autologous transgene-activated periosteal cells in a porcine model of osteoarthritis. Arthritis \& Rheumatism: official. J Am Coll Rheumatol. 2008;58(2):475-88.

22. Goldring MB. The role of cytokines as inflammatory mediators in osteoarthritis: lessons from animal models. Connect Tissue Res. 1999;40(1):1-1.

23. Sieker JT, Proffen BL, Waller KA, Chin KE, Karamchedu NP, Akelman MR, Perrone GS, Kiapour AM, Konrad J, Murray MM, Fleming BC. Transcriptional profiling of articular cartilage in a porcine model of early post-traumatic osteoarthritis. J Orthop Res. 2018:36(1):318-29.

24. McCulloch RS, Ashwell MS, Maltecca C, O'Nan AT, Mente PL. Progression of gene expression changes following a mechanical injury to articular cartilage as a model of early stage osteoarthritis. Arthritis. 2014:371426.

25. McCulloch RS, Ashwell MS, T O'Nan A, Mente PL. Identification of stable normalization genes for quantitative real-time PCR in porcine articular cartilage. J Anim Sci Biotechnol 2012:3:36

26. Steibel JP, Poletto R, Coussens PM, Rosa GJ. A powerful and flexible linear mixed model framework for the analysis of relative quantification RT-PCR data. Genomics. 2009;94:146-52.

27. Reiner A, Yekutieli D, Benjamini Y. Identifying differentially expressed genes using false discovery rate controlling procedures. Bioinformatics. 2003;19: 368-75

28. Xu Y, Barter MJ, Swan DC, Rankin KS, Rowan AD, Santibanez-Koref M, Loughlin J, Young DA. Identification of the pathogenic pathways in osteoarthritic hip cartilage: commonality and discord between hip and knee OA. Osteoarthr Cartil. 2012;20:1029-38.

29. Peffers MJ, Liu X, Clegg PD. Transcriptomic signatures in cartilage ageing. Arthritis Res Ther. 2013;15:R98.

30. Fitzgerald JB, Jin M, Dean D, Wood DJ, Zheng MH, Grodzinsky AJ. Mechanical compression of cartilage explants induces multiple timedependent gene expression patterns and involves intracellular calcium and cyclic AMP. J Biol Chem. 2004;279:19502-11.

31. Van der Kraan PM, Van den Berg WB. Chondrocyte hypertrophy and osteoarthritis: role in initiation and progression of cartilage degeneration? Osteoarthr Cartil. 2012;20:223-32

32. Swingler TE, Waters JG, Davidson RK, Pennington CJ, Puente XS, Darrah C, Cooper A, Donell ST, Guile GR, Wang W. Degradome expression profiling in human articular cartilage. Arthritis Res Ther. 2009:11:R96.

33. Kim HA, Lee YJ, Seong S, Choe KW, Song YW. Apoptotic chondrocyte death in human osteoarthritis, J Rheumatol. 2000:27:455-62.

Ready to submit your research? Choose BMC and benefit from:

- fast, convenient online submission

- thorough peer review by experienced researchers in your field

- rapid publication on acceptance

- support for research data, including large and complex data types

- gold Open Access which fosters wider collaboration and increased citations

- maximum visibility for your research: over $100 \mathrm{M}$ website views per year

At $\mathrm{BMC}$, research is always in progress.

Learn more biomedcentral.com/submissions 